\title{
A novel approach to the aneurysmal coronary artery fistula
}

\author{
Christopher H. May, MD, ${ }^{\mathrm{a}}$ Douglas R. Johnston, MD, ${ }^{\mathrm{b}}$ Wael A. Jaber, MD, ${ }^{\mathrm{a}}$ and \\ Gosta B. Pettersson, MD, PhD, ${ }^{\mathrm{b}}$ Cleveland, Ohio
}

Coronary artery fistulas are a rare subset of coronary artery anomalies, with a prevalence of approximately $0.2 \%{ }^{1}$ They involve an abnormal connection between a coronary artery and a cardiac chamber or large thoracic vessel such as the coronary sinus or pulmonary artery. The majority are small fistulas, which are well tolerated and typically found incidentally. A large fistula causes symptoms of high cardiac output failure, such as dyspnea, fatigue, angina, and volume overload. The coronary artery feeding the fistula can dilate and become aneurysmal. In cases of large symptomatic fistulas, surgical repair is imperative to stop progression of symptoms and return the patient to his or her prior functional status. When the coronary artery is substantially dilated, simple ligation of the fistula may not be the best option because of increased risk of thrombosis or rupture. The following report describes a novel surgical solution to this problem.

\section{CLINICAL SUMMARY}

A 44-year-old woman had worsening shortness of breath and was found to have a gigantic coronary artery fistula between the circumflex artery and coronary sinus. At maximum diameter, the circumflex artery was $2.3 \mathrm{~cm}$ and the coronary sinus was $4 \mathrm{~cm}$ (Figure 1). There was significant left-to-right shunting with a pulmonary/systemic flow ratio of 2.35. Echocardiogram revealed a moderately dilated left ventricle with a normal ejection fraction, moderately severe mitral regurgitation, moderate tricuspid regurgitation, and an estimated right ventricular systolic pressure of $71 \mathrm{~mm}$ Hg. Initially, she declined surgical repair owing to the high risk of the operation; however, her symptoms progressed and she agreed to proceed.

The patient was placed under general anesthesia and a median sternotomy was performed. The left internal thoracic artery (LITA) and saphenous vein graft were harvested. Cardiopulmonary bypass was established and the aorta crossclamped. The heart was arrested with antegrade cardioplegia. The aneurysmal left circumflex artery

\footnotetext{
From the Medicine Institute, Department of Cardiovascular Medicine, ${ }^{\mathrm{a}}$ and the Heart and Vascular Institute, Department of Thoracic and Cardiovascular Surgery, ${ }^{b}$ Cleveland Clinic, Cleveland, Ohio.

Disclosures: Authors have nothing to disclose with regard to commercial support.

Received for publication Dec 9, 2011; accepted for publication Dec 21, 2011; available ahead of print Jan 30, 2012.

Address for reprints: Gosta B. Pettersson, MD, PhD, Cleveland Clinic Foundation, 9500 Euclid Ave, Mail Code J-41, Cleveland, OH 44195 (E-mail: petterg@ ccf.org). J Thorac Cardiovasc Surg 2012;144:265-7

$0022-5223 / \$ 36.00$

Copyright (C) 2012 by The American Association for Thoracic Surgery doi:10.1016/j.jtcvs.2011.12.046
}

was ligated at its proximal end, divided proximally, and opened down to the insertion into the coronary sinus. Seven coronary branches were identified. The left circumflex artery's insertion into the coronary sinus was closed. The coronary sinus was reduced to about 1.5 $\mathrm{cm}$ and closed longitudinally. The ramus branch was mobilized and anastomosed to the left anterior descending artery with 7-0 monofilament suture. Six of 7 branches of the circumflex artery were sequentially grafted, and a tiny atrial branch was oversewn. Three distal posterolateral branches were revascularized with sequential anastomoses to the ostia using the free LITA. Three obtuse marginal branches were revascularized in the same way with sequential vein anastomoses. The proximal end of the vein was anastomosed to the aorta and the LITA was anastomosed to the vein graft (Figure 2). The mitral valve was repaired with an annuloplasty ring. Aortic crossclamp time was 187 minutes and cardiopulmonary bypass time 212 minutes.

After 24 hours, the patient underwent re-exploration for bleeding. No anastomotic bleeding was found. The remainder of her hospital course was unremarkable. She was discharged on postoperative day 11 .

\section{DISCUSSION}

This case demonstrates a novel technique for securing revascularization in a patient with a large coronary artery fistula and subsequent dilation of the involved artery. Owing to

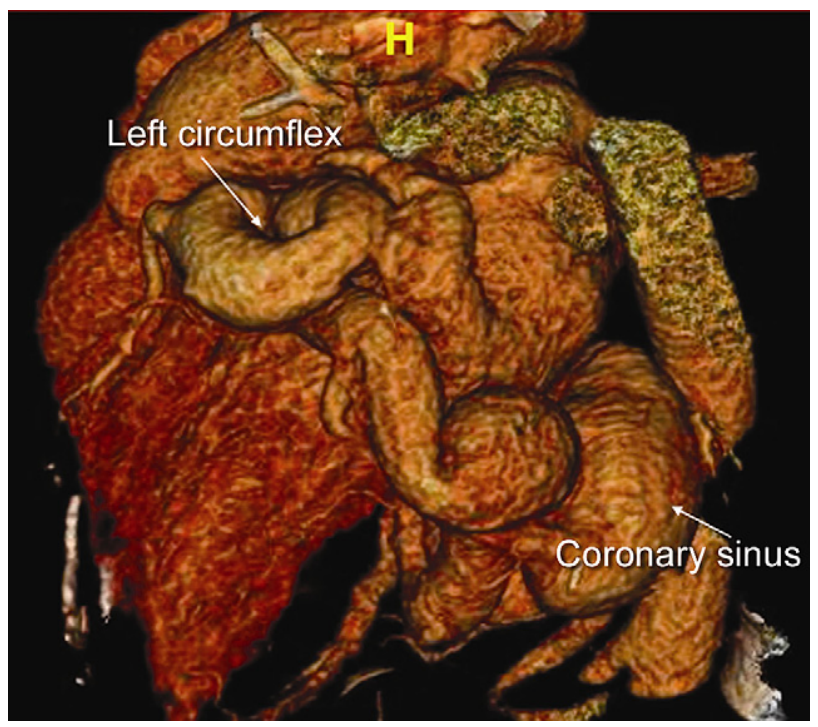

FIGURE 1. Preoperative cardiac computed tomogram demonstrating left circumflex-coronary sinus fistula. 


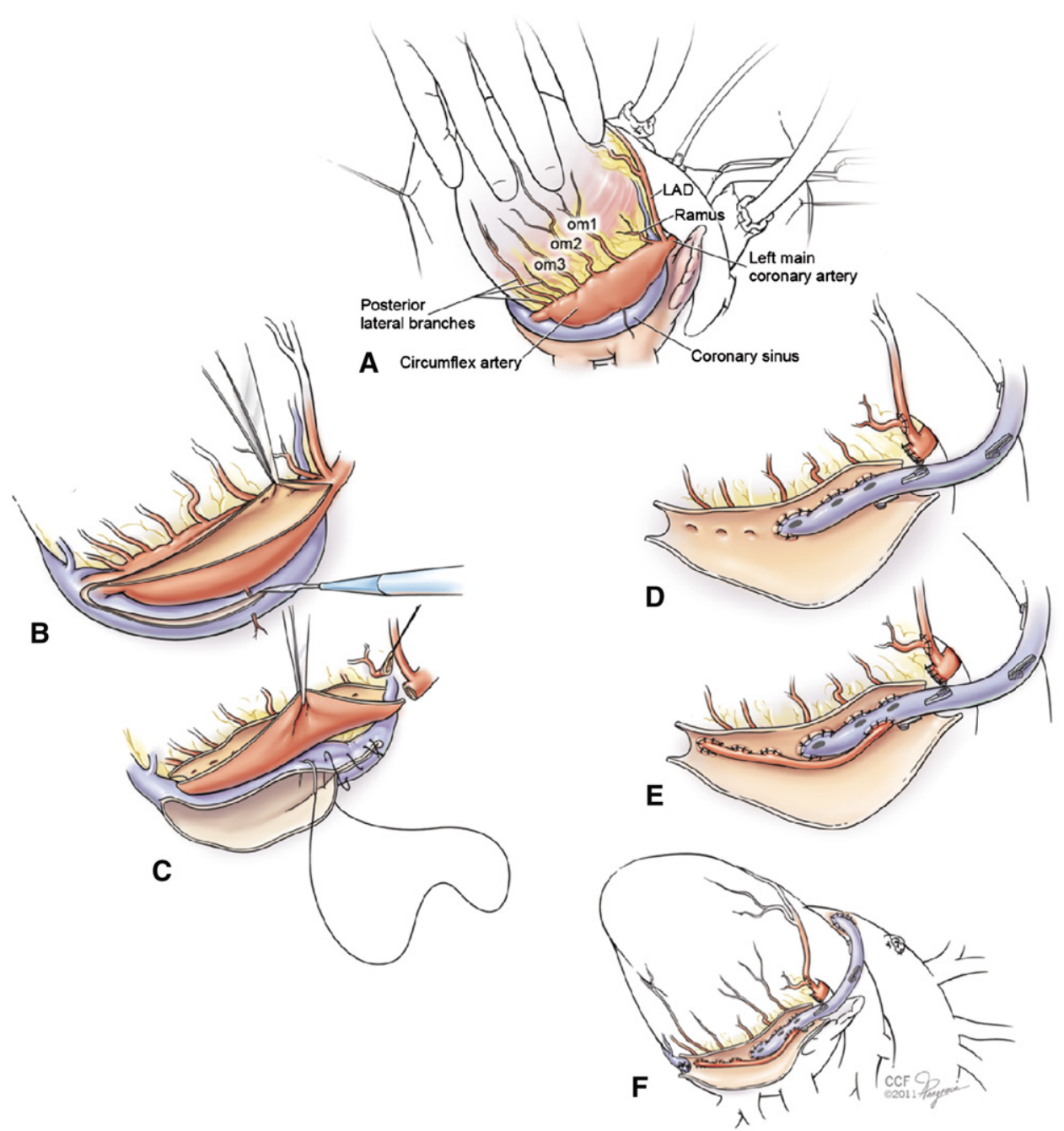

FIGURE 2. A, Initial view of left circumflex fistula. B, Dividing the left circumflex artery and coronary sinus. C, Closing the coronary sinus longitudinally. $\mathrm{D}$, The ramus branch anastomosed to the left anterior descending artery and 3 obtuse marginal branches revascularized with sequential vein anastomoses. E, The 3 distal posterolateral branches revascularized with sequential anastomoses using the free left internal thoracic artery graft, which is itself anastomosed to the vein graft. F, Final operative result. $L A D$, Left anterior descending artery; om, obtuse marginal branch.

the left circumflex artery's slow postligation flow into the coronary sinus, ligating it at its insertion site would lead to significant risk of rupture ${ }^{2}$ or thrombosis. ${ }^{3}$ Likewise, performing left circumflex artery plasty to create a smaller lumen would subject the patient to an increased risk of thrombosis owing to the long suture line. Performing bypass without surgical exploration of the left circumflex to identify the ostium of each branch would have been problematic inasmuch as preoperative angiography did not identify any graftable branches owing to difficulty filling the gigantic vessel with contrast. In addition, this patient had small targets for bypass.

The inspiration to graft the ostium of each branch came from a technique used in bronchial artery revascularization, previously described in patients undergoing lung transplant. ${ }^{4}$ In brief, the internal thoracic artery revascularizes the bronchial arteries through sequential anastomoses to each bronchial artery ostium in the donor descending aorta. Conventional bypasses to these branches are not possible owing to their small size. With ostial grafting, size is not a technical issue, although poor runoff may still be problematic, particularly for the final branch.

It is now more than 4 years since the operation and the patient remains symptom free, with excellent functional status. This operation is an effective solution to aneurysmal coronary arteries associated with large fistulas. The aneurysmal component of the artery is no longer at risk for thrombosis or rupture, and complete revascularization prevents postoperative myocardial infarction or ischemia.

We thank Dr Debbie Kwon for providing the cardiac computed tomographic image. 


\section{References}

1. Yamanaka O, Hobbs RE. Coronary artery anomalies in 126,595 patients undergoing coronary arteriography. Cathet Cardiovasc Diagn. 1990;21: 28-40.

2. Nakahira A, Sasaki Y, Hirai H, Fukui T, Motoki M, Takahashi Y, et al. Rupture of aneurysmal circumflex coronary artery into the left atrium after ligation of its arteriovenous fistula. Circ J. 2007;71:1996-8.
3. Loo B, Cox ID, Morgan-Hughes GJ, Marchbank AJ. Thrombotic occlusion of giant circumflex artery aneurysm after ligation of arteriovenous fistula. Circulation. 2010;122:e447-8.

4. Pettersson G, Norgaard MA, Arendrup H, Brandenhof P, Helvind M, Joyce F, et al Direct bronchial artery revascularization and en bloc double lung transplantation—surgical techniques and early outcome. J Heart Lung Transplant. 1997; 16:320-33.

\title{
Staged Kawashima operation with cavopulmonary connection
}

\author{
Yogesh Sathe, FNB, Shanthi Chidambaram, FNB, Krishna Manohar, MCh, and
}

Kotturathu Mammen Cherian, FRACS, Chennai, India

We herein present our technique of staging the Kawashima procedure in a child with single ventricle and interruption of the inferior vena cava (IVC) with fair-sized pulmonary arteries by creating a bidirectional cavopulmonary anastomosis first, followed by Fontan completion as the second stage.

\section{CLINICAL SUMMARY}

A 3.5-year-old girl weighing $10 \mathrm{~kg}$ with tricuspid atresia, ventricular septal defect, and pulmonary stenosis with fair-sized pulmonary arteries was taken for bilateral bidirectional cavopulmonary anastomosis on the basis of echo-

From the Department of Pediatric Cardiology and Cardiac Surgery, Frontier Lifeline and Dr K M Cherian Heart Foundation, Chennai, India.

Disclosures: Authors have nothing to disclose with regard to commercial support.

Received for publication Oct 26, 2011; revisions received Dec 17, 2011; accepted for publication Jan 4, 2012; available ahead of print Feb 13, 2012.

Address for reprints: Yogesh Sathe, FNB, Department of Pediatric Cardiology, R-30-C, Frontier Lifeline Hospital, Chennai, India (E-mail: satheyogesh74@ rediffmail.com).

J Thorac Cardiovasc Surg 2012;144:267-8

$0022-5223 / \$ 36.00$

Copyright (C) 2012 by The American Association for Thoracic Surgery

doi:10.1016/j.jtcvs.2012.01.007 cardiography in 2001. At surgery, absent right superior vena cava (SVC) and interrupted IVC with hemiazygos continuation to a large left SVC and joining of hepatic veins to the right atrium were noted. On cardiopulmonary bypass, the left SVC was divided above the hemiazygos vein and anastomosed to the left pulmonary artery as a left bidirectional Glenn shunt, leaving the IVC drainage unchanged. Because the pulmomary artery mean pressure was $18 \mathrm{~mm} \mathrm{Hg}$, the pulmonary trunk was banded to allow a limited antegrade flow (Figure 1, A) She made a good recovery but was lost to follow-up after 2 years.

She returned at the age of 13 years (2010) with progressive effort dyspnea and worsening cyanosis (arterial oxygen saturation, 72\%).A cardiac catheterization showed a wellflowing left-sided Glenn shunt and IVC drainage via the hemiazygos vein into the coronary sinus through the proximal left SVC (Figure 2). There were no pulmonary arteriovenous malformations or venovenous collaterals.

During Fontan completion, the hemiazygos vein was disconnected from the left SVC stump and anastomosed end to side to the left pulmonary artery, completing the Kawashima procedure. The hepatic veins were connected to the right pulmonary artery with an $18-\mathrm{mm}$

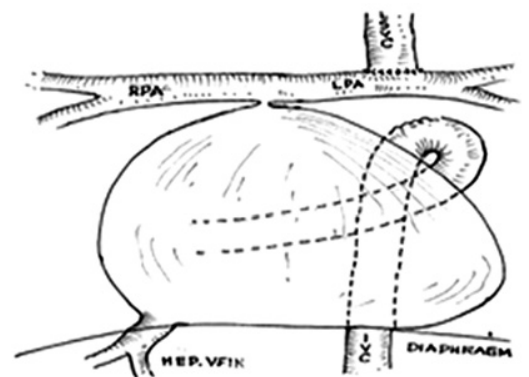

A

FIGURE 1. A and B, Kawashima completion by direct hemiazygos to left pulmonary artery connection and extracardiac hepatopulmonary connection to the right pulmonary artery completing total cavopulmonary connection. The pulmonary trunk was interrupted. $I V C$, Inferior vena cava; $L S V C$, left superior vena cava; RPA, right pulmonary artery; LPA, left pulmonary artery; HEP. VEIN, hepatic vein. 